\title{
A Portrayal of the Sexual and Reproductive Perceptions of Women with Disabilities Using An Overarching Critical Feminist Disability Lens
}

\author{
Barbra Mapuranga $^{1} \quad$ Maxwell C.C. Musingafi ${ }^{2 *}$ \\ 1.Zimbabwe Open University, Department of Special Needs Education, Faculty of Applied Social Sciences. \\ 2.Zimbabwe Open University, Department of Development Studies, Faculty of Applied Social Sciences.
}

\begin{abstract}
This paper is developed from our study on sexual and reproductive rights of women with disability in Zimbabwe, The paper demonstrates how the social model, human rights-based and feminist approaches combine to come up with an overarching critical feminist disability studies lens (CFDSL) to guide studies on disability and feminism using sexual and reproductive rights of women with disabilities. The paper argues that gender and disability are not only complex, but very dynamic and fluid problems. They cannot be adequately investigated using the lens of one simple theory. Hence the need for theory triangulation to come up with some hybrid theory like CFDSL. From the perspectives of the CFDSL, therefore, this paper argues that women with disabilities are not any special case who should be simply pitied without access to human rights which are mandatory to every human being. They are different, but this difference does not imply denial of human rights, in this case sexual and reproductive rights.
\end{abstract}

Keywords: women, disability, theory, sex, framework, gender.

DOI: $10.7176 /$ RHSS/9-18-03

Publication date:September $30^{\text {th }} 2019$

\section{Introduction}

Like any other social phenomena and cross-cutting issues, gender and disability are not only complex, but very dynamic and fluid problems. Therefore, they cannot be adequately investigated using the lens of one simple theory. In such cases the solution is theory triangulation to come up with some hybrid theory. This involves integrating and synthesising a number of related concepts and theories to view the problem from a more enlightened angle. In line with this thinking, we are proposing a conceptual framework, which integrates related theoretical concepts under an overarching critical feminist disability studies lens (CFDSL). This hybrid lens seeks to mitigate the scarcity of contextual theoretical perspectives on the gender and/or feminism and disability studies. As this particular hybrid lens is derived from the social model, feminist and human rights-based approaches, it therefore follows that a brief exposition of the social model and rights based approaches is required before delving into the hybrid and overarching critical feminist disability studies lens.

\section{The social model}

The social model views disability as a consequence of environmental, social and attitudinal barriers that prevent people with impairments from enjoying human rights (Oliver, 1983; 1990). Thus, it can be argued that women with disabilities fail to enjoy their sexual and reproductive rights because of the way society conceptualises these rights and not because of their impaired bodies (Oliver, 1990). The major criticisms of the model have been that it is not enough to explain everything that troubles persons with disabilities. However, no theory in life has ever explained everything and as the proponents of the model always maintain, the model was not designed to be a tool for the exhaustion of understanding disabilities but was meant to be a political tool to deal with disabling barriers in the same way that a hammer is used (Oliver, 2013; 1990; 1983).

\section{Human rights-based approaches}

The social model has been subjected to various transformations and has given birth to human rights-based approaches (HRBA) to disability. While there are academics who believe that the HRBA is a successor to the social model, it is here argued that the HRBA is simply an elaboration of the social model. The HRBA to disability assumes that rights naturally flow that someone especially the state is obliged to fulfil that right. In this study therefore, the understanding is that women with disabilities have sexual and reproductive rights which the state and society are obliged to fulfil (Oliver, 2013).

\section{Feminism}

Feminism is about challenging gender inequalities to liberate women in the social world. A more detailed description of feminism is given by Maguire (1987) who sees it as involving the belief that women universally face some forms of oppression and exploitation, a commitment to uncover and understand what causes and 
sustains oppression in all its forms and a commitment to work individually and collectively in everyday life to end all forms of oppression. This clarifies the fact that feminism is based on the belief that women are disadvantaged because of their sex and that this disadvantage can and should be removed. Most feminists insist that gender differences are entirely cultural and hence are imposed upon individuals by society (Heywood, 1992; Eisenstein, 2002; Musingafi, Dumbu and Chabaya, 2013).

\section{The critical feminist disability studies lens (CFDSL)}

Peta (2015) sees the CFDSL integrated theory as an 'overarching critical feminist disability studies lens' integrating related theoretical concepts on disadvantaged groups like women and the disabled. As illustrated in fig. 1, the point of intersection for all the theoretical models is what is being referred to as CFDSL.

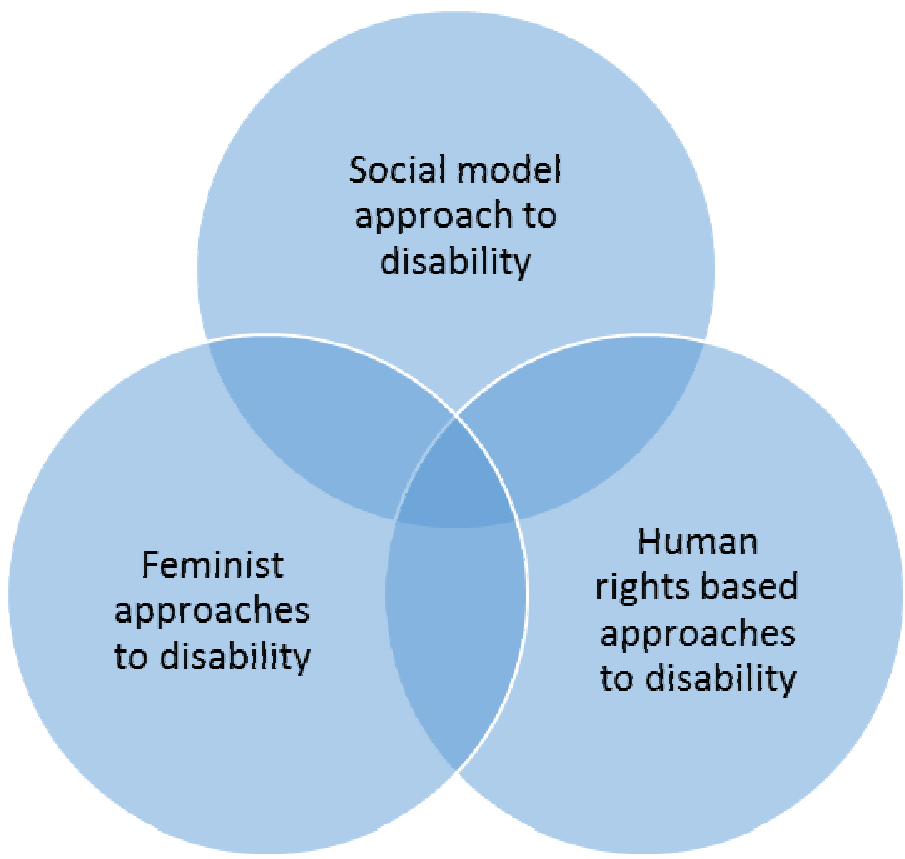

Fig 1: The critical feminist disability studies lens

According to Meekosha (2004), CFDSL seeks to understand disability from a gender point of view, following the mainstream feminist marginalisation of women with disabilities' experiences. Disability feminist advocates like Meekosha and Shuttleworth (2009) contest the masculine structure of the disability movement in which the voice of women with disabilities has been missing. In fact, CFDSL scholars argue that the experiences of women with disabilities within heteronormative contexts differ in relation to issues such as menstruation, reproduction, abortion, child-rearing and sterilisation among others (Peta, 2015). A key argument of CFDSL is that disability is a social construction which relegates disability to a category of inferiority (Garland-Thomson, 2005).

CFDSL argues that our communities are characterised by thoughts, customs, organisations and social relations that assume that disability is a defect or a deficiency (Peta, 2015). Thus, CFDSL do not delineate disability as a flaw that is integral to certain brains or bodies, but a system of denigrating or ignoring certain bodies (Garland-Thomson, 2005). Viewed from such a lens, disability is a way in which people think about bodies and not anything that is really faulty with bodies (Malmberg, 2009). For example, people may think that all people who are visually impaired are so "damaged" that they do not want to have sex, yet the reverse may be true. Nevertheless, such perspectives permeate cultures and authenticate inequalities in the distribution of status, capital and power (Garland-Thomson, 2011).

Peta (2015) observes that instead of focusing on precise forms of disability and how such bodies behave, CFDSL concentrates on probing the types of meaning that are assigned to the bodies. As CFDSL moves towards inclusion from exclusion, the approach seeks to rescue silenced voices and experiences that have not been properly represented, thereby facilitating the accommodation of bodies instead of the condemnation of them (Garland-Thomson, 2011). Whilst mainstream feminist discourses view women with disabilities as women with individual "tragedies" that require private personal attention, charity or care, CFDSL challenges the perception that women with disabilities are sub-standard, deficient, excessive, incompetent, unhealthy and useless (Peta, 2015).

Where disability studies theories examine the identity marker of disability in pursuance of an understanding and total inclusion of disabled people in society (Garland-Thomson, 2011), the feminist discourse seeks to 
expand the understanding of women (Garland-Thomson, 2005, 2011). This does not, however, mean that CFDSL becomes a simple combination of feminism and disability studies, but CFDSL facilitates the reimagining of disability (Garland-Thomson, 2005) as well as the re-imagining of gender (Hall, 2011). In fact, CFDSL does not simply add the experiences of women with disabilities to feminist literature or to disability studies (Peta, 2015). It modifies both fields as it seeks to deepen the feminist analyses of disability, body politics, oppression, interdependency and agency (Erevelles, 2011; Garland-Thomson, 2005); and embraces different sexual orientations to cater for those who may not access sexual gratification the conventional way.

CFDSL acknowledges the significant gender debates in which some leading feminist scholars (Zinanga, 1996; Meekosha, 2004) have pointed at varied sexual orientations such as trans-genders, lesbians and gays and noted that gender is an unstable and fluid fiction which changes periodically within varying contexts. However, many a legal framework, most people and their cultures denounce different sexual orientations other than heterosexuality. In most communities, homosexuality is linked to witchcraft and evil spirits that should be dealt with privately and at family level (Epprecht, 1998).

Disabled people are generally believed to be asexual beings who, due to their bodily differences, do not require any form of acknowledgement in the arena of sexuality (Lloyd, 2001; Ghai, 2002; Malmberg, 2009). In fact, women with disabilities are not only seen as asexual but unattractive and unbefitting as parents (GarlandThomson, 2005; Lloyd, 2001). Disability thus, "erases all the other qualities of a human being, thereby reducing the complex being to a single social life attribute such as disability, at the express exclusion of all of an individual's other identity markers such as sexuality, class, gender or culture" (Peta, 2015. P.16). Women with disabilities are thus denied the right to intimate relationships, personal satisfaction, marital unions and motherhood (Lloyd, 2001). Wilkerson (2011) claims that the sexuality of women with disabilities is usually regarded as a social problem, a practice which in itself is a symbol of oppression. When the body is regarded as the conduit between sexuality and sexual roles, the position of women with disabilities in non-normative body images may weaken their case of being perceived as sexual beings, particularly in reproduction where they are expected to prove that they are functionally capable (Lloyd, 2001).

In most communities across the world people believe that all incapacities of women with disabilities are biological, that they have no sexual feelings and that they will produce defective children (Banks \& Kaschak, 2003). Women with disabilities living in institutions are worse off, as they are likely to experience a loss of their sexual agency due to a lack of privacy which prevails in residential institutions (Wilkerson, 2011). Living under the watchful eye of institutional staff, disabled people who may have met at an institution and fallen in love are forced to meet in communal areas such as dining halls where every other person can hear even that which they whisper to each other (Ball, n.d).

From a CFDSL standpoint, one could argue that the sexist nature of the society in which both women with disabilities and non-women with disabilities' lives generates the kind of knowledge that frames the type of appearance that women seek to have (Morris, 2001). A disabled woman may begin to believe that she is ugly to the extent that she will not be able to undress in front of others or her husband and she may even despise her own body (Peta, 2015). Such situations may arise when a woman judges her own body in accordance with the societal template of attractiveness, thereby derailing her own self-esteem and sexual confidence (Malmberg, 2009). In such a context the woman feels that she has to hide her body which she views as one that is missing the mark of established standards of beauty (Saxton, 1985). Furthermore, throughout the world, women with disabilities are constantly bombarded with media messages that encourage them to buy products that alter certain aspects of their appearance so that their bodies may conform to established societal standards. Within African contexts, feminine beauty is framed around the notion of being a huge and plump nondisabled woman (MakinwaAdebusoye and Tiemoko, 2007).

The CFDSL, therefore, argues that women with disabilities are not any special case who should be simply pitied without access to human rights which are mandatory to every human being. They are different, but this difference does not imply denial of human rights, in this case sexual and reproductive rights.

\section{Conclusion}

The paper established that gender and disability are not only complex, but very dynamic and fluid problems. It argued such complex phenomena cannot be adequately investigated using the lens of one simple theory. This situation calls for theory triangulation to come up with some hybrid theory like CFDSL. From the perspectives of the CFDSL, the paper further argues that women with disabilities are not any special case who should be simply pitied without access to human rights which are mandatory to every human being. The paper argued that women with disabilities are different, but this difference does not imply denial of human rights, in this case sexual and reproductive rights.

\section{References}

Ball, K. F. (n.d.). Sexuality is our basic human right. In Women and disability an issue. Melbourne: Women with 
disabilities Australia. Retrieved from Error! Hyperlink reference not valid.. 25 August, 2017.

Banks, M. E., and Kaschak, E. (2003). Women with visible and invisible disabilities, multiple Intersections, multiple issues, multiple therapies. New York: The Haworth Press.

Eisenstein, Z. (2002) What's in a name? Seeing feminism, universalism and modernity. Excerpts(with permission) from against empire, feminisms, racism and fictions of the west. Zed Press.

Epprecht, M. (1998). The 'unsaying' of indigenous homosexualities in Zimbabwe: mapping a blindspot in an African masculinity. Journal of Southern African Studies, 24(4). Pp. 631-651.

Erevelles, N. (2011). The colour of violence: Reflecting on gender, race, and disability. In K. Hall (Ed.), Feminist disability studies (pp. 118-135). Bloomington: Indiana University Press.

Garland-Thomson, R. (2005). Feminist disability studies. Signs, 30(2). Pp. 1557-1587.

Garland-Thomson, R (2011). Misfits: A feminist materialist disability concept. Hypatia, 26(3). Pp. 591-609.

Ghai, A. (2002). Disabled women: An excluded agenda of Indian feminism. Hypatia 17(3). Pp. 49-66.

Hall, K. Q. (2011). Reimagining disability and gender through feminist studies: An introduction.In K.Q. Hall (Ed.), Feminist disability studies (pp.1-10). Bloomington: Indiana University Press.

Heywood, A. 1992. Political ideologies: an introduction. New York: Palgrade.

Lloyd, M. (2001). The politics of disability and feminism: Discord or synthesis? Sociology. Pp. 35(3), 715-728.

Maguire, P. (1987). What makes feminist research feminist?: Doing participatory research: a feminist approach. Massachusetts: University of Massachusetts.

Makinwa-Adebusoye, P. and Tiemoko, R. (2007). Introduction: Healthy sexuality discourses in East, West, North and southern Africa. In E. Maticka-Tyndale, R. Tiemoko, and P. Makinwa-Adebusoye (Eds.), Human sexuality in Africa: Beyond reproduction (pp.116). Auckland Park: Jacana Media.

Malmberg, D. (2009). Body-normativity - Reading representations of disabled female bodies. In J. Bromseth, L. F. Kall, and K. Mattson (Eds.), Body claims. Uppsala: University Printer.

Meekosha, H. (2004). Gender and disability: Sage Encyclopaedia of Disability .http://pf7d7vi404s1dxh27mla5569.wpengine.netdnacdn.com/files/library/meekoshameekosha.pdf. Accessed 25 June 2017.

Meekosha, H. and Shuttleworth, R. (2009). What's so 'critical' about critical disability studies? Australian Journal of Human Rights. 15(1). Pp. 47-75.

Morris, J. (2001). Impairment and disability. Constructing an ethics of care that promotes human rights. Hypatia 16(4). Pp. 1-16

Musingafi, M.C.C., Dumbu, E. and Chabaya, O. (2013). Gender dynamics: Development and peace studies perspectives. New York. IISTE.

Oliver, M. (1983). Social Work with Disabled People. Basingstoke: Macmillan.

Oliver, M. (1990). The Politics of Disablement. Basingstoke: Macmillan.

Peta, C. (2015). Voices from the periphery: a narrative study of the experiences of sexuality of disabled women in Zimbabwe: PhD thesis. Cape Town. University of Cape Town.

Saxton, M. (1985). A peer counselling training program for disabled women: A tool for social and individual change. In M.J. Deegan and N.A. Brooks (Ed.), Women and disability: The double handicap. New Brunswick: Transaction Books.

Wilkerson, A. (2011). Disability, sex radicalism and political agency. In K. Hall (Ed.), Feminist disability studies (pp. 194-217). Bloomington: Indiana University Press.

Zinanga, E. (1996). Sexuality, identity and change. Southern Africa Feminist Review, 2(1), 36. 